\title{
The Effect of Henna in Nail Changes Due to Paclitaxel Treatment
}

\author{
(1) Emel Emine KAYIKÇl, ' (1) Gülbeyaz CAN² \\ 'Department of Nursing, Istanbul Medeniyet University Faculty of Health Sciences, Istanbul-Turkey \\ ${ }^{2}$ Department of Nursing, Istanbul University-Cerrahpasa Florence Nightingale Faculty of Nursing, Istanbul-Turkey
}

\section{Dear Editor,}

Paclitaxel, a member of Taxane family, causes various side effects that negatively affect the life quality of the patients. One of these side effects is nail toxicity that develops in all or some of the nails.[1] In the present case report, it was aimed to emphasize that henna application may be effective in the management of nail changes in a patient with metastatic breast cancer receiving paclitaxel, regarding the recovery of nail changes without interrupting the treatment of the patient.

A 51-year-old female patient was admitted to the outpatient chemotherapy unit for the $32^{\text {nd }}$ week of weekly paclitaxel treatment with the diagnosis of metastatic breast cancer. When the history of the patient was taken, during the paclitaxel treatment, it was determined that nail changes started in the patient after the $3^{\text {rd }}$ week of treatment. The patient reported that "I cannot touch my fingertips and my nails anywhere, otherwise I have too much pain, my nails smell very bad." In addition, the patient had discoloration of her nails and onycholysis. The patient was very uncomfortable with the appearance of her nails and she was trying to hide her nails (Fig. 1).

Henna application was recommended to the patient for the treatment of nail changes. She was asked to do this twice a week in such a way that henna will always be present on the nails. Then, the changes on the nails of the patient were followed weekly (Fig. 2). The patient was followed up for a total period of 7 weeks, and at the end of the $7^{\text {th }}$ week, all the problematic parts were detached and replaced with new nails (Fig. 3).

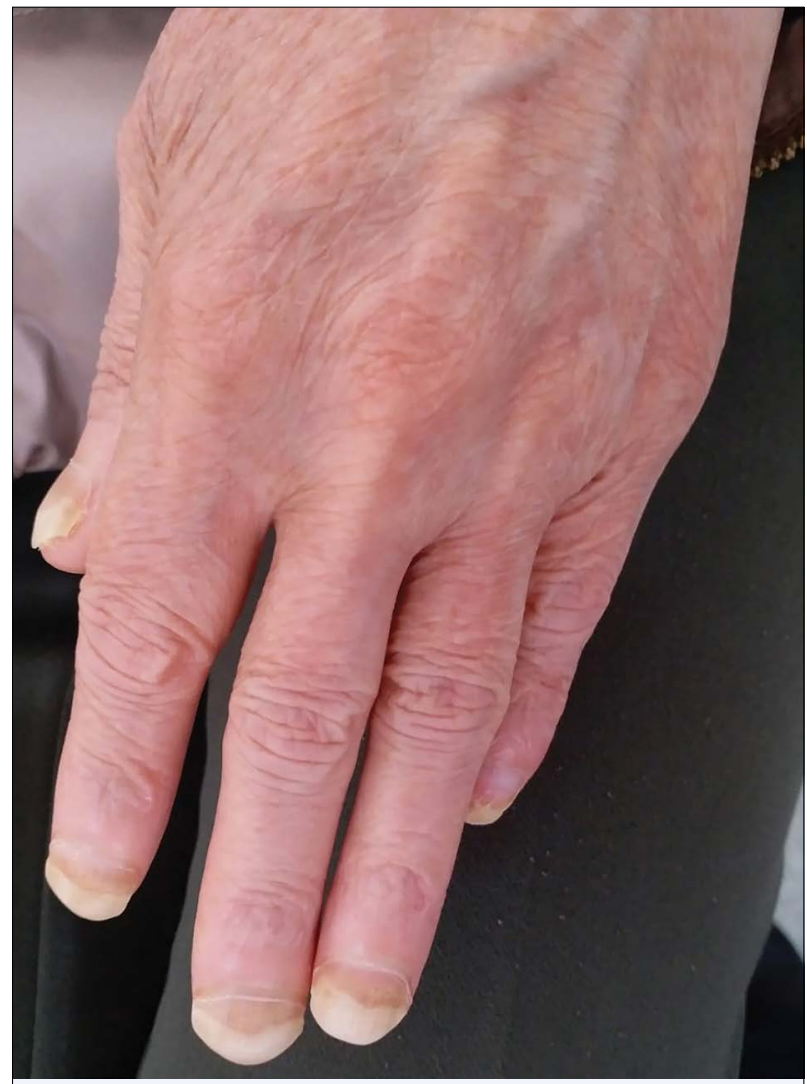

Fig. 1. Initial evaluation. Pain, tension, onychosis, and smell in the nails.

Nail changes related to chemotherapy cause cosmetic problems, pain, and infection and negatively affect the life quality of the patients.[1]

The studies have revealed that henna has antibacterial, antifungal, analgesic, and anti-inflammatory ef- 


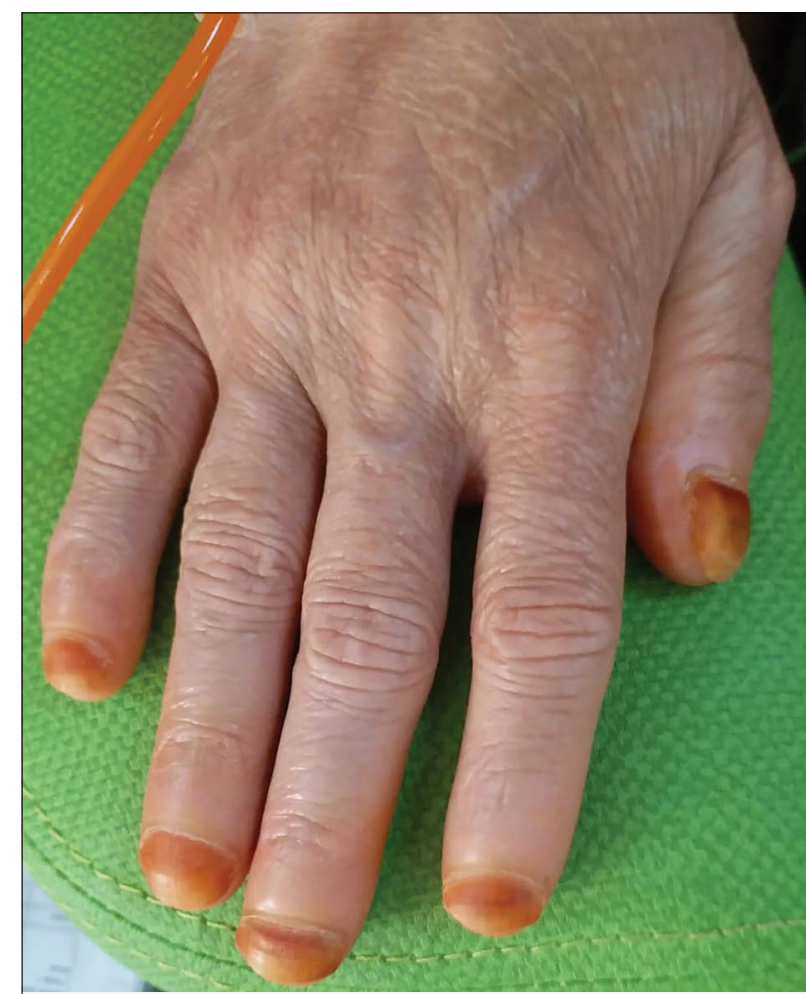

Fig. 2. 1. week. Decrease in pain and tension in the nails, the bad nail smell was eliminated and instead henna smelled. Visually good appearance.

fects. In addition, the antifungal, antioxidant analgesic, anti-inflammatory, and antipyretic effects of henna are shown by rat studies. [2-5]

When the literature is examined, henna was applied in two small-scale studies, one of which was a case report, to recover the hand-foot syndrome related to chemotherapy. According to the results of the studies, complete recovery was generally achieved in the patients, but a decrease was observed in the grade of hand-foot syndrome of some patients.[6,7]

Based on this study, the healing effect of henna in the nail changes related to chemotherapy was evaluated because the anti-inflammatory, antipyretic, and analgesic effects of henna are known.

It was observed that henna primarily removed bad smell in nail changes seen in the present case, reduced pain, and provided relief, and then healed onycholysis. Moreover, in the present study, the patient stated that she applied easily henna, experienced no difficulty during the application, she considered its smell as pleasant and its smell did not bother her.

Consequently, we are of the opinion that henna application can help in improved nail changes caused by the treatment in the patient.

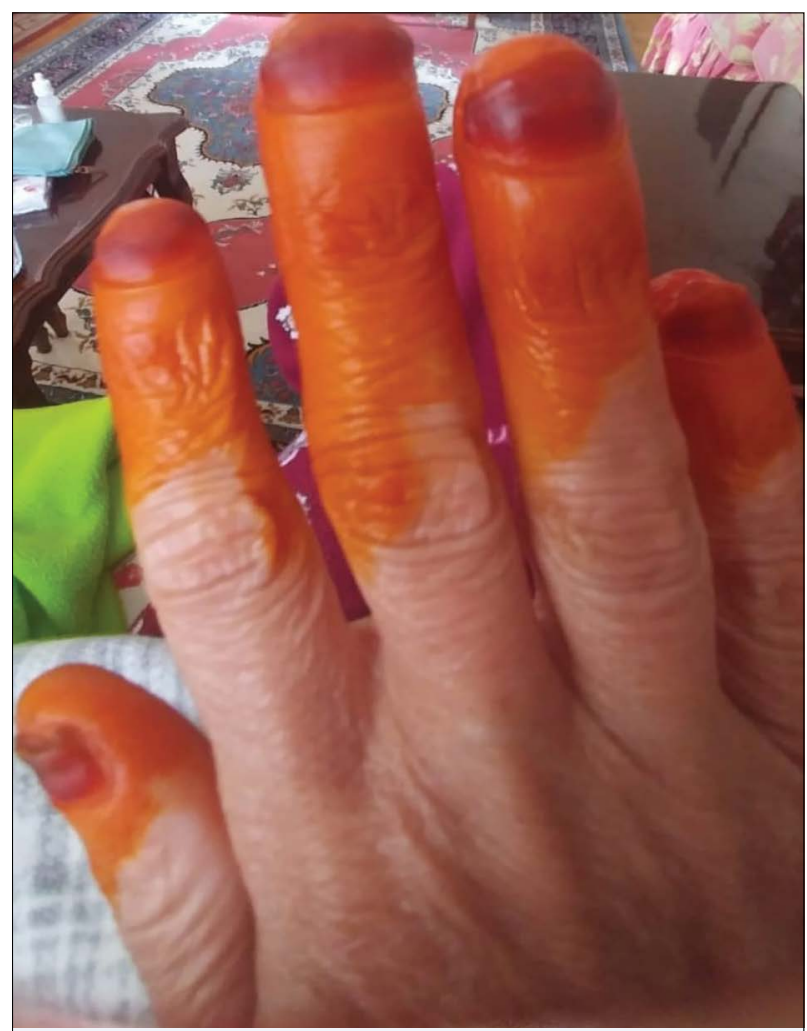

Fig. 3. 7. week. Nails were growing and complete recovery was present.

\section{References}

1. Capriotti K, Capriotti JA, Lessin S, Wu S, Goldfarb S, Belum VR, et al. The risk of nail changes with taxane chemotherapy: A systematic review of the literature and metaanalysis. Br J Dermatol 2015;173(3):842-5.

2. Ali BH, Bashir AK, Tanira MO. Anti-inflammatory, antipyretic, and analgesic effects of Lawsonia inermis L. (henna) in rats. Pharmacology 1995;51(6):356-63.

3. Rahmoun N, Boucherit-Otmani Z, Boucherit K, Benabdallah M, Choukchou-Braham N. Antifungal activity of the Algerian Lawsonia inermis (henna). Pharm Biol 2013;51(1):131-5.

4. Mutluoğlu M, Uzun G. Can henna prevent ulceration in diabetic feet at high risk? Exp Diabetes Res 2009;2009:107496.

5. Mikhaeil BR, Badria FA, Maatooq GT, Amer MM. Antioxidant and immunomodulatory constituents of henna leaves. Z Naturforsch C 2004;59(7-8):468-76.

6. Yucel I, Guzin G. Topical henna for capecitabine induced hand-foot syndrome. Invest New Drugs 2008;26(2):189-92.

7. Ilyas S, Wasif K, Saif MW. Topical henna ameliorated capecitabine-induced hand foot syndrome. Cutan Ocul Toxicol 2014;33(3):253-5. 